\title{
Translation
}

\section{Sentiment: The Basis for Developing Aesthetic Judgment}

\author{
Marjan Michels ${ }^{1}$, Wil Meeus ${ }^{2} \&$ Johan De Walsche ${ }^{1}$ \\ ${ }^{1}$ Department of Architecture, Faculty of Design Sciences, University of Antwerp, Belgium \\ ${ }^{2}$ Didactica research group, Antwerp School of Education, University of Antwerp, Belgium \\ Correspondence: Marjan Michels, Department of Architecture, Faculty of Design Sciences, University of \\ Antwerp, Mutsaardstraat 31, 2000 Antwerp, Belgium. E-mail: marjan.michels@uantwerpen.be
}

Received: February 1, 2016

Accepted: February 3, $2016 \quad$ Online Published: February 29, 2016

doi:10.20849/aes.v1i1.33

URL: http://dx.doi.org/10.20849/aes.v1i1.33

This article was originally published in Dutch on Tijdschrift Voor Hoger Onderwijs, Vol. 32 No. 4, 2014. This article was translated into English by the authors.

\begin{abstract}
Consciously or unconsciously, programmes in higher education maintain a value framework about the aesthetic value of students' work, primarily based on the ability of such work to touch or move us. We consider something aesthetically valuable when it makes us feel good. In an educational environment, however, dealing with aesthetic value judgments pedagogically is complicated. After all, aesthetic judgment is a skill that cannot be taught explicitly; it can only be practised. This article discusses the underlying mechanisms of aesthetic judgment. The aim is to gain a better understanding of this skill and thus to contribute to the development of a pedagogy of aesthetic judgment. Relying on a theoretical framework developed on the basis of a literature review, we suggest that judging aesthetic value is an emotional process that requires well-formed aesthetic sentiment. Architectural education is an interesting case because it is a field in which aesthetic values occupy a central position. This study is therefore illustrated with examples from this field.
\end{abstract}

Keywords: aesthetic judgment, architectural education, emotion, sentiment, values

\section{Introduction}

Values reflect what a group or community considers to be good or bad, and therefore what is or is not worth pursuing. A community's way of thinking and view of the world is determined by its values. While values are not often presented deliberately or explicitly, they inevitably shape the perspective from which a community acts and reacts. Values appear in all the facets of a culture, from politics and religion to company strategies, novels and dance performances. As a result, they are an inherent aspect of our educational systems, dictating school culture, teachers' educational practice and course content.

This article focuses on the education of students, and in particular on aesthetic training as part of a higher education degree programme. Consciously or unconsciously, educational programmes maintain a value framework which is applied when assessing students' assignments. All types of assignment - whether written essays or presentations, mathematical proofs or electromechanical models, class performances or architectural designs - can either make an evaluator feel good or leave him or her entirely unmoved. What exactly leads to a better result depends, among other things, on the context and the prevailing value framework. Yet the basis of an assignment's success appears to lie in its ability to touch us emotionally: besides meeting a number of agreed criteria, students are expected to produce assignments that are surprising or convincing, fascinating or charming. It is the pleasure reflected in these emotional responses to a piece of work that constitutes its aesthetic quality.

Aesthetic education enables students to interpret and act within the culture of their education (Friberg, 2011). Thus, it trains them to produce work which will be judged to be of good quality within the culture of their programme. An assignment may meet all of the predefined criteria, but it is its aesthetic value that will determine whether it is judged to be outstanding. However, dealing with aesthetic values pedagogically is complicated. No simple norms or rules can be applied to produce a fascinating essay, a convincing class performance or a 
beautiful design. Helping students to achieve aesthetic quality involves coaching them in making appropriate assessments and decisions at the right time: decision points emerge constantly during the processes of creating, writing essays, preparing courses, designing architectural project, and so on. Should I use this expression or a different one? Should I combine this material with this colour? Of course, what was a good choice in one context is not guaranteed to work in another situation. It is aesthetic judgment which enables us to make the best decision in a specific situation involving numerous constraints and uncertainties. This faculty of aesthetic judgment cannot be learnt simply by following and applying explicit rules: 'Applying rules is a matter of judgment and judgment cannot be taught, only practiced (Kant, 1790).' The outcome of such practice is a refined aesthetic sensibility. One area in which this refined sensibility inevitably comes to the fore is in the judgment of aesthetic value (Friberg, 2011).

This article elaborates on the skill of aesthetic judgment, also called the judgment of taste. A better understanding of this skill may provide a basis for developing its teaching in higher education. Education in the field of architecture is an interesting case, because it is a discipline in which aesthetic values occupy a central position. The study is therefore illustrated with examples from architectural education.

\section{Sentiment: The Basis for Developing Aesthetic Judgment}

\subsection{Architectural Education}

Architecture is a discipline that is strongly determined by the framework of cultural values inherent to a community. While internal structures regulate this value framework, the discipline is also influenced by the Zeitgeist and society (Hays, 1984). Because architecture evolves to keep pace with social trends and new visions, 'aesthetic quality' must be seen as culturally, contextually and historically relative. Obviously, for cultural-historical reasons, architecture can touch us across both time and culture.

During architectural training, students inevitably come in contact with the prevailing value framework. The aim of architectural training is to help students become competent designers of the spatial environment, which involves the sustainable organisation of humans' physical surroundings. In other words, it involves the competent use of spatial elements to meet people's physical, social, aesthetic and moral needs (VLIR, 2011). At the basis of this thinking in the Western world lies the triad of Roman architect and engineer Vitruvius, dating from the 1st century BC. Vitruvius taught that a structure should possess three qualities: firmitas (stability), utilitas (functionality) and venustas (beauty). Even today, there is a broad consensus that the architectural quality of a design is determined by its ability to balance these three Vitruvian virtues (Volker, Lauche, Heintz, \& de Jonge, 2008). Every spatial design - a chair, a room, a building - should conform to technical, functional and aesthetic needs. As aesthetic judgment clearly constitutes a substantial aspect of design skill, aesthetic training should also play a primary role in architectural education.

The design studio is the ideal arena in which to allow aesthetic judgment to emerge during architectural training. Learning by doing - with the aid of an instructor, who acts as a coach, expert and critic - students gradually master new design skills. The instructor makes the student aware of the many standards and rules for designing functional and technically sound projects during weekly feedback sessions, during which the aesthetic quality of each design proposal is discussed in terms of good, bad, interesting or exciting (Schön, 1984). Through this process of designing and interacting with their instructors, students gradually develop a sense of aesthetic judgment.

\subsection{Aesthetic Judgment}

According to Prinz (2007) and Robinson (2005), aesthetic judgment is related to emotions. Several studies in current brain research have indicated that certain regions of the human brain which are activated during aesthetic appreciation are also highlighted in emotion studies (Kawabata \& Zeki, 2004; Vartanian \& Goel, 2004). Aesthetic quality cannot be seen objectively as a characteristic of the thing in question, but it is an attribute that we, individuals, attach to it during the process of judging. Thus, if we label something as having aesthetic quality, we only mean that it leads us to experience pleasure and 'satisfaction of the soul'.

'But beauty of all kinds gives us a peculiar delight and satisfaction; as deformity produces pain. [...] Pleasure and pain, therefore, are not only necessary attendants of beauty and deformity, but constitute their very essence.' (Hume, TIII, 2, viii, 1)

It is important to note that subjectivity does not necessarily lead to relativity. Aesthetic appreciation is not a private, subjective matter: norms and standards about what is generally considered good or bad are inevitably formed in all communities. Each community also has connoisseurs, whose taste is considered better than average. Connoisseurship is reserved for individuals with certain qualities who have refined those qualities by experience. 
'If $[\ldots]$ there be an entire or considerable uniformity of sentiment among men, we may thence derive an idea of the perfect beauty. [...] And the joint verdict of such, wherever they are to be found, is the true standard of taste and beauty.' (Hume, SOT, 12/23)

Aesthetic quality in architecture is considered to be a subjective perception, since the judgment of aesthetic quality is emotionally embedded and thus personal. However, the standard of architectural aesthetic values is accepted by the community and enforced by the judgments of architectural experts.

According to Schumacher (2011), rationalising the aesthetic value of a design result would lead to infinite indecision: 'Beauty must be shrouded in mystery in order to fulfil its function in the design process, a function that truth cannot fulfil: to bring the design process to conclusion, move by move, decision by decision.' Rather than being founded in rationality, then, appropriate aesthetic judgment should arise out of an appropriate emotional response. In order to develop aesthetic judgment among students, it is crucial to cultivate their emotions by practising, critiquing and comparing with the aesthetic judgments of their instructors. As mentioned above, it is not through lecturing on theories of taste, quality or judgment that students will develop good aesthetic judgment: only by practising and interacting with the culture in which they participate will their aesthetic judgment develop. Once they have acquired a well-formed aesthetic judgment, students will be capable of actively controlling and evaluating the aesthetic quality of their designs themselves. Consequently, the skill allows students to interpret the value framework of the contemporary culture of architecture, to act within it and to become experts in their discipline.

\subsection{Judging: An Emotional Process}

The mechanism underlying judging is essentially an unconscious process that involves emotions. A better understanding of this mechanism could help in developing a pedagogy of aesthetic judgment. Briefly put, an emotion is a spontaneous evaluation of circumstances in the environment, either harmful or beneficial, which enables a fast, appropriate reaction. Both the external environment and an internal, mental idea are evaluated in order to determine the personal meaning of the situation for the individual.

'The biological function of a human emotion is to alert the person to something in the internal or external environment which is of vital importance to the organism's interests, goals, values, well - being or survival.' (Robinson, 2005, p. 46)

Experiencing emotions is a biological mechanism that has evolved in humans and which serves as a very primitive survival system. In today's cultivated and complex world, the mechanism has become increasingly refined. An evaluative judgment is thus an appraisal of a situation in terms of one's own desires, values and beliefs. If something in an individual's environment is harmful or not useful, or hinders them from reaching their goal, then they are likely to feel unhappy or dissatisfied. Conversely, if something in the environment conforms to their values, is important or helps them achieve a goal, they will feel happy or satisfied. These feelings then help them to act in the situation concerned.

Initially, the emotional or bodily response - a physiological reaction such as increased heart rate or change in facial or vocal expression - is triggered by an unconscious affective appraisal. Affective appraisals proceed more quickly than higher cognitive processes, but ultimately lead to a limited number of primitive options, like the freeze, fight or flight reactions (Lyons, 1980). Subsequently, a cognitive appraisal monitors the initial affective appraisal and, if necessary, corrects the bodily and emotional responses. This cognitive appraisal is the moment at which the internal thoughts and/or external circumstances are perceived more precisely in terms of one's own interests, values or goals (Ledoux, 1996). At the end of this unconscious, spontaneous process, we become aware of our bodily responses and reflect upon our emotional response. We label such responses by describing how we are feeling; for example, we might feel good or happy, or perhaps dissatisfied or afraid. Feelings are an 'after-the-fact assessment' (Robinson, 2005) (Figure 1).

Internal or external events can also be associated with positive or negative emotions through a process of bodily imprinting known as somatic marking (Damasio, 1994). Based on past emotional experiences in particular situations, an individual might have a similar affective reaction in a similar situation in the future. This is because he or she has stored up a kind of 'bodily marked memory'. Through learning experiences, emotions become linked to the anticipated outcomes of scenarios. When a negative somatic marker is associated with a particular future outcome, the combination functions as an alarm bell. When a positive somatic marker is involved, on the other hand, it serves as a kind of stimulant (Damasio, 1994). 


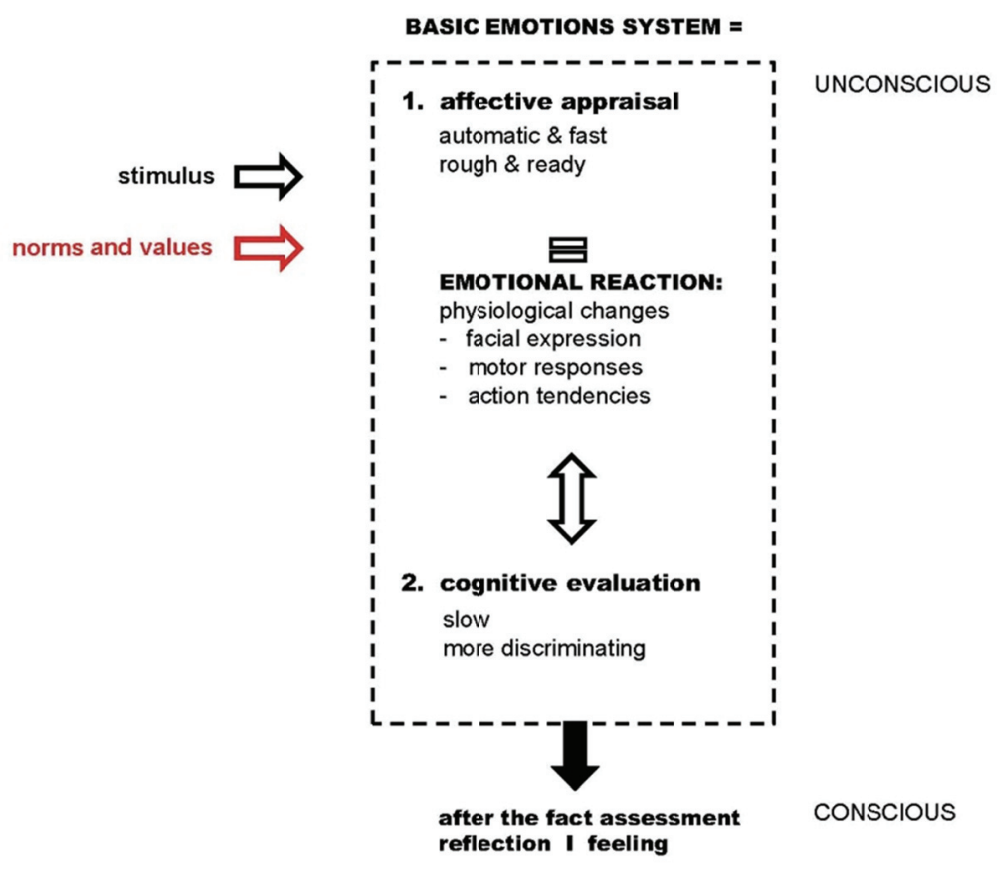

Figure 1. The emotional process of judging

\subsection{Architectural Sentiment}

According to our study, making an aesthetic judgment during the design process involves experiencing either positive or negative emotions when imagining or perceiving the tentative design result. This feeling constitutes the basis for the approval or disapproval of the design decision in terms of the aesthetic values promoted by a particular architectural culture. The culture of the design studio, the institute or the broader community to which the institute belongs are all potential frames of reference for students during this process.

In the design studio, it is important to develop students' aesthetic judgment consciously and intentionally. Not all aesthetic judgments will eventually become adequate aesthetic judgments. In the context of developing a pedagogy, the concept of architectural sentiment may serve as a basis upon which to build. Architectural sentiment is defined as the competence to judge adequately the aesthetic quality of architectural design. This entails, firstly, that a student has the capacity to experience emotions - in other words, to have bodily reactions to particular affective stimuli - when perceiving an architectural design and evaluating its qualities. Prinz (2011) defines this sentiment as 'a disposition or second nature to have emotions'. When a student has developed a well-formed architectural sentiment, he or she will be able to react emotionally in an appropriate way when perceiving architectural design. Previous experiences will have allowed him or her to attach positive somatic markers to the dominant aesthetic values and negative somatic markers to designs which do not conform to these values. In this way, the student will have developed a second nature, guaranteeing that he or she will spontaneously and unconsciously feel good when perceiving aesthetic quality in architecture and feel bad when encountering a design that could be considered inferior in the cultural environment. The architecture student thus internalises the aesthetic values of his or her cultural environment and shapes his or her sentiment to the culture of architecture.

\subsection{Individual Freedom in the Design Studio}

Communication lies at the heart of teaching and learning in the design studio (Vowles, 2000). While designing, students engage in dialogue with themselves, their fellow students, their instructors and the imagined users of the fictional project. They learn through interaction with their cultural contexts, among other things. Throughout their educational careers, students continually construct and reconstruct their identities in this setting (Webster, 2006). Novices develop their aesthetic judgment by testing themselves against the values of their instructors, the culture of the studio and by extension the culture of the institute. Gradually, students learn to develop the 
appropriate emotional reactions through experience. They also learn to discriminate between their emotional reactions and fine-tune them through higher cognitive processes in dialogue with others. It is through communication and interaction that the standard of what is considered aesthetic quality is shared. As students progress, however, their instructors encourage them to set their own priorities and to tread new paths. Subsequently, they themselves may bring new perspectives into the studio. Eventually, the students evolve into peers and come to shape the culture of the studio themselves. After all, innovation is key to design in architecture. Architecture involves creating a new future every time from a critical perspective; it is a discipline in which the ruling standards are being constantly challenged (Geldof \& Janssens, 2007). As a result, the standards in the design studio are dynamic for both students and instructors. The culture of the design studio thus forms a value framework, continuously evolving, to which all members will contribute and by which their sentiment will be formed.

\section{Conclusion}

Consciously or unconsciously, educational programmes maintain an aesthetic value framework which is applied in the evaluation of students' assignments. The aesthetic quality of a work consists in its capacity to surprise and to please. We consider something to be aesthetically valuable when it makes us feel good. Some educational programmes, such as architecture, acknowledge that aesthetic values are an essential element of their students' training. In most programmes, however, aesthetic values are addressed only implicitly, while nevertheless dictating judgments of quality. Higher education practice could benefit from paying more attention to aesthetics in a structural way. For instructors, for example, it is important to be aware of the aesthetic processes that lie beneath their evaluations of students' work. For students, too, it would be beneficial to learn to recognise and appreciate the aesthetic dimensions of their work and to become sensitive to them. Aesthetic training would enable students to interpret and act within the cultures of their educational programmes. With a good sense of the prevailing values, they can more easily interact with their cultural environments in an effective way, meaning they can take the most appropriate decisions intuitively and produce good quality, innovative work. Becoming an expert in a discipline requires that one develops a sensitivity to the prevailing value framework and the capacity to apply it. The development of an appropriate pedagogy may contribute to this. Addressing aesthetic values pedagogically is complex, however. Helping students achieve aesthetic quality involves coaching them in making appropriate aesthetic judgments at the right time. As mentioned above, aesthetic judgment is a skill that cannot be taught explicitly: it develops gradually through practice in interaction with the culture of the educational programme.

The concept of sentiment may be a useful tool in developing a pedagogy of aesthetic judgment. As described above, a well-formed aesthetic sentiment is a prerequisite for developing adequate aesthetic judgment. It is a cultivated attitude, a second nature, which ensures the production of an appropriate, spontaneous emotional reaction to an aesthetic stimulus. An individual reacts emotionally because the stimulus either conforms to or conflicts with his or her aesthetic values. Gradually, through experience, this individual has developed a well-formed sentiment within the value framework of the surrounding culture.

In the context of education, developing good aesthetic judgment consciously and effectively will consist in helping students first to develop a well-formed sentiment. At the heart of a pedagogy for aesthetic judgment lies a concern for naming aesthetic values, for practising judgment in interaction with the culture of the educational programme, for treating emotions as a form of knowledge, and for shaping emotional reactions against a dynamic value framework. The methodology can be applied to a range of disciplines. Group discussions about the aesthetic quality of a novel, for example, may contribute to the development of a well-formed literary sentiment. Trainee teachers who practise in interaction with instructors and peers, meanwhile, will develop a well-formed didactic sentiment. Similarly, paying attention to the emotional language used during peer assessment of a technical design could help stimulate the development of a sentiment for industrial design.

How a pedagogy of aesthetic judgement could be developed in practice should be the focus of further research. A constructivist educational philosophy could serve as a starting point for this research. In this philosophy, emotion is recognised as a type of knowledge, and learning is structured around the relation between the individual and his or her cultural environment (Biesta \& Miedema, 1999). The application of these views to enable the forming of aesthetic sentiment requires further study.

\section{References}

Biesta, G., \& Miedema, S. (1999). John Dewey: Filosoof van opvoeding en democratie. Ter inleiding. [John Dewey: Philosopher of education and democracy. An introduction.] In J. Dewey (Original work published 
1916), Ervaring en opvoeding [Experience and education] (pp. 9-38). Houten/Antwerp: Bohn Stafleu Van Loghum.

Damasio, A. (2006). Descartes' error: Emotion, reason, and the human brain. London: Vintage Press.

Friberg, C. (2011). Contemporary Culture and Aesthetic Education. In I. F. Dorsch, J. Stejskal, \& C. Todd (Eds.), Proceedings of the European Society for Aesthetics, 3, 104-114.

Geldof, C., \& Janssens, N. (2007). Van ontwerpmatig denken naar onderzoek [From design thinking to research]. In K. Vandermarliere et al. (Eds.), Achtergrond \#03 - Architect/ontwerper/onderzoeker? Casus mare meum: een oefening op zee [Background \#03 - Architect/designer/researcher? Casus mare meum: an exercise at sea]. Merendree: Drukkerij St Joris.

Hays, M. (1984). Critical architecture: Between culture and form. Perspecta, 21, 14-29. http://dx.doi.org/10.2307/1567078

Hume, D. (1739-40/2000). A treatise of human nature (D. F. Norton, \& M. J. Norton, Trans.). Oxford - New York: Oxford University Press. (referenced with siglum T)

Hume, D. (1757/1965). Of the standard of taste, and other essays (J. W. Lenz, Trans.). Indianapolis: Bobbs Merrill. (referenced with siglum SOT)

Kant, I. (1914). Kant's critique of judgement (J. H. Bernard, Trans.). London: Macmillan.

Kawabata, H., \& Zeki, S. (2004). Neural correlates of beauty. Journal of Neurophysiology, 91, 1699-1705. http://dx.doi.org/10.1152/jn.00696.2003

Ledoux, J. (1996). The emotional brain: The mysterious underpinnings of emotional life. New York: Simon \& Schuster.

Lyons, W. E. (1980). Emotion. Cambridge studies in philosophy. Cambridge: Cambridge University Press. http://dx.doi.org/10.1017/CBO9780511609244

Prinz, J. (2007). Emotion and aesthetic value. Retrieved from http://subcortex.com

Prinz, J. (2011). Morality is a Culturally Conditioned Response. Philosophy Now. Retrieved from http://www.philosophynow.org/issue82

Robinson, J. (2005). Deeper than reason. Emotion and its role in literature, music and art. New York: Oxford University Press. http://dx.doi.org/10.1093/0199263655.001.0001

Schön, D. (1984). The architectural studio as an exemplar of education for reflection-in-action. Journal of Architectural Education, 38, 2-9. http://dx.doi.org/10.2307/1424770

Schumacher, P. (2011). The autopoiesis of architecture. Volume 1. A new framework for architecture. Chichester UK: John Wiley \& Sons.

Vartanian, O., \& Goel, V. (2004). Emotion pathways in the brain mediate aesthetic preference. Bulletin of Psychology and Arts, 51, 37-42.

Vlir. (2011). De onderwijsvisitatie Architectuur [Education audit: Architecture]. Retrieved from http://www.vlir.be/media/docs/Visitatierapporten/2011/VLIRarchitectuur_def.pdf

Volker, L., Lauche, K., Heintz, J. L., \& De, J. H. (2008). Deciding about design quality: design perception

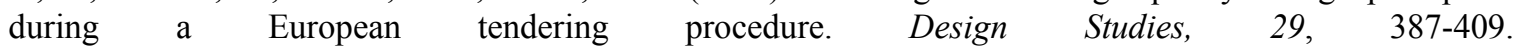
http://dx.doi.org/10.1016/j.destud.2008.03.004

Vowles, H. (2000). The crit as ritualised legitimation procedure. In D. Nicol, \& S. Pilling, (Eds.), Changing architectural education (pp. 223-227). London: E \& F Spon.

Webster, H. (2006). Power, freedom and resistance: Excavating the design jury. International Journal of Art and Design Education, 25, 286-296. http://dx.doi.org/10.1111/j.1476-8070.2006.00495.x

\section{Copyrights}

Copyright for this article is retained by the author(s), with first publication rights of English version granted to the journal.

This is an open-access article distributed under the terms and conditions of the Creative Commons Attribution license (http://creativecommons.org/licenses/by/3.0/). 